\title{
The Formation Reasons of Ideological Content and Style for The Reader
}

\author{
Liu Jin \\ Nanchang Institute of Science \&Technology,Nanchang 330108,China
}

Key words: The Reader; ideological content; character features; artistic charm

\begin{abstract}
The Reader is a film adapted by Stephen Daldry from the novel of the same name, the film tells the hobbling lifetime story of a man and a woman, they bear historical yoke, gently destroyed each other's lives. In this paper, the humanity and dignity story of The reader has been analyzed from the film ideological content and character features in literature and film,, the method of close reading has been used to show its artistic charm. The reader not only has reflection and criticism of the war, morality, ethics, love, betrayal, redemption and human nature, but also contains very complex emotion, and the guilt of the historical need to face by the world. The research on the content and style of The reader is of great importance in literary value and practice.
\end{abstract}

\section{Introduction}

The reader is a film adapted by Stephen Daldry from the novel of the same name. The reader has two awards of Hans faret award and World news literature award, which shows its literary achievements. The reader film adapted from the novel, has won the 2009 Golden Globes, and Oscar award, which contains a profound meaning, and includes a strong religious flavor. This paper will describe the behavior of Hanna from the perspective of western religion in the study of characters. German literature during World War II has been known as "ruins literature", the post-war ruins, not only exists in the city and countryside, but also exists in the people's ideals and ideology. Their works often take a fragment of life as the content with simple language, but not plain and tasteless, no climax, no preaching, but has a profound shock. Because of simple language, but not plain and tasteless, and simple and powerful content of the fragments, and often be ranked as a classic film or documentary. The literature in this period reflects a large extent the subject of war, ethics, ethics, betrayal, redemption, humanity, love, sadness, sadness, joy, and noble. Therefore, it is of great importance in literary value and practice to study the stylistic features of German literature in this period.

\section{The ideological content of The Reader}

The director uses the way of "the other" that be designed and be watched to show the main body of independent thought. The narrators converts themselves to directors, which is from a narrative angle of "omnipotent" hidden behind the character to show the movie's authenticity, and narrative methods has been converted polyphonic to monologue, a patchwork of such simple film image will lead to novel lose its unique charm, in other words, some images in the movie are just more purely to show accurately the people's of behavior, character, and can not increase connotation of the film. For Hanna why joined the Nazi party, and why suddenly left, why acknowledged publicly that report is she personally wrote in Court, the answer that given by the film is: Hannah believes that it is a very shameful thing that admitting she was illiterate in the front of her beloved person, and her reverence for knowledge has surpassed her fear of evil. She would rather receive shame and 
punishment of becoming Nazi accomplice due to inability to read and write and join the Nazi party, than exposing the fact that she is an illiterate. This also indicates that she would rather be in prison for the main reason is that she thinks there is no ability to read and write is a very shameful thing. From the film, we have very accurate answer, but the film has reduced much of the story relatively the novel, such as in novel Hanna's eyes for the first time into the study of Mike's father and the misunderstanding caused by Mike leave note when their travel together. After the film has been omitted from the original very important episode, it appears that it is difficult to understand the decision of Hanna joining the Nazi Party.

All bedding and narrative of the Film the reader is to show a clear answer: Hannah can give up everything in order to be able to hold her own the secret of inability to read and write, such as career, love, even life. Director has submerged the main character and other people's consciousness and voice in his own subjective imagination, therefore, the audiences have been brought to the only way leading to a deep inside character, and have no other choice, only following the director's footsteps. The author believes that the film is mainly to show all kinds of important circumstances in the original, and not having too many adaptations, so that the audience can still be a good understanding of the story in the novel. The classical and naturalistic narrative style have been used in the film, which main emphasis on the unity of the drama, credibility and coherence, and not let the audiences think the story is virtual, and each shot is leaving no trace, smoothly once a plot into a plot.

\section{Characters of Hanna in The reader}

From Mike has loved Hannah, who is more than twenty years old, to the joy of their body and soul; from Hannah suddenly disappear to she became the defendant in court; from Mike understand his love secret and Hannah previous guilt; then to Hannah has hanged herself before release from prison, which has enough made an impact on the audience. At the same time, it also attracts readers to think and analyze the mystery of Hanna. Hannah has doped too many contradictions, she is a woman Mike loved, always detergents smell in outside her house. She was wearing stockings ecstasy, she lingered in the appearance in front of the shelves. These are all revealed her beauty and kindness. But she also worked as a guard in the concentration camp: she picked inmates to death, even kill them in order not to let her secret be known; she put too much emphasis on their work, resulting in the fire to hundreds of inmates died; from Mike said school like a fool as to Anna found Mike leave note angry; turn away from her when a tram driver to a concentration camp guard; and she was admitted not to write the report. Her performance shows that she has an extremely strong sense of inferiority and shame because of illiteracy. For Hannah, the sense of shame to her was too great, and she believes that it is more terrible thing that admitting she was illiterate in the front of her beloved person in public, than the one who confessed himself to be a criminal. We can not simply judge Hanna's choice, we can not make a decision for her, and can not overthrow the things that people themselves. Her inner truth and justice of their own, she would use her self-image to absolve herself crimes. Hanna loves Mike, but she doesn't want him to find that she is an illiterate. When she received the tape of Mike, she began to learn literacy in prison, and take the courage to let Mike find the facts of illiterate, but it is failed to receive a letter from Mike. When she realized that Mike could not stay with her, she would have no place to go, she chose to commit suicide. 


\section{Betrayal and redemption}

The film "The Reader" has made the greatest achievement is that the despair of sigh can be seen from the film, and the fear of death, as well as the hero and heroine inner monologue, sin and repentance. This thing Hannah betrayal Mike in the film, the so-called silent love is the best evidence of betrayal: in the imagination circles is they are alone in the world or in his heart of hearts that Hannah. At the same time, it shows that Mike loves Hanna very much is Mike's concession to Hanna time and time again. But this kind of love is very difficult to continue down in the real world and the imaginary, when Mike left Hanna back to now in the world. He was tired, and avoided this love, or even wanted to get rid of the burden and impact brought about by the feeling. Accurately speaking, Mike in the subconscious that the love between he and Hanna is a shameful thing, just like Hanna thought that it was shameful to be illiterate. However, when they meet in court, one is a promising young man with a bright future, and the other one is a criminal subjected to the censure of everybody, Mike dodge eyes deeply hurt Hannah, she already did not have the courage to face anyone, also feel no need to justify herself. The author thinks that one of the reasons why Hanna chose to bear all the guilt is due to Hanna's desperate to Mike. Mike also felt invisible punishment due to Hannah, he even think that "as long as she could go to jail, she will disappear in my world and my life, I want to let her become the memories of my life, precipitation in my memory." Mike has made a decision not to save and distressed Hannah, each other disappeared in their own world. Hanna's betrayal is to subvert the conscience, the reason of she joining the Nazi SS is to stick to her own inner secret. She ruined her life for her secret, it seems there is no doubt that is a foolish choices for we these reading and writing ability of the people.

Hannah is a illiteracy who extreme pursuit and longing for knowledge, in the heart of Hannah, knowledge is human dignity in the world, she built her dignity by the reading sound of others, The only spiritual need of Hannah is to be able to express her opinions freely, this is also the reason she finally went astray. We can not understand the pressure and mental torture Hanna suffered during those dark days, and this is the pain she is not willing to touch. Although she joined the SS were in her way in no way, but she still have the courage to admit she was voluntary. As a person of betrayal of the conscience, Hannah has become an accomplice of Nazi SS from an ordinary woman, the reason is very complicated, let us have infinite compassion and emotion to her: everyone has the right to choose their own life, but it is a fate and history of cutting, we can not put all the mistakes for Hanna to bear. There are a lot of people like Hanna in the concentration camp. They are more or less with a surprised day Holocaust related to a certain extent, but many people have not been investigated both legal and moral responsibility after the war, perhaps the evil time just appeared in their restless dreams, the potential punishment exists only in the corner of the deep in the hearts of the people, then gradually be forgotten. Mike is also a victims of Hannah's crime facts, he found that the crime by many common commit was to let a few accomplices in the bear, which is very unfair for the accomplice. But Hannah and her parents must pay for their sins and accept punishment. Only in this way, they in the face of those innocent died wronged people, can they have a clear conscience. When compared with the suffering and suffering of people, his love for Hanna was negligible. In this view, Hanna also got emotional and moral punishment because of his betrayal of conscience, that is Mike's final despair on Hanna.

Redemption is an important theme of the Western World War II as the theme of the works, of course, The reader is the same routine. Why Hannah take all responsibility in the concentration camp, not only she has always been that want to keep a secret, but also Hannah needed for her crimes to pay the price from another report in the film. There are many confessions of her heart, her 
many emotional control is mainly her reflection of guilt, she hopes to obtain forgiveness and victim, but she can not ask for sympathy, because no matter what, she has caused great physical and psychological harm to the victims, she did not dare to absolve herself of those extremely brutal crimes. Therefore, she received a life in prison for this harsh trial, hoping to wash her heart of dirt and guilt, she can only use this method to get their own inner comfort.

The hero of the film Mike is a betrayal of love, he used the method of reading the tape for Hanna to make an atonement for himself. He made use of the recording way to achieve communication with Hanna heart, because reading was their most affectionate means once, so that he could be able to get the heart of salvation. But the love between he and Hanna before has become the past, he can not cross the prison break inside and outside the prison, can only hide in the tape of the world silence and repentance. Mike only once to visit Hanna in a few days before Hannah released, Mike could not persuade himself to let Hannah and him live together after Hannah was released from prison, and Hannah understood they have no way to then the same as ever, including reading, everything has become the past smoke. Hanna chose to die to escape the tragic and helpless life outside the prison. After Hanna passed away, Mike deposit 7000 to a victim in accordance with the will of her, but the victim did not accept it. She said: "Forgiveness is the only that I can neither give nor grant." The film is full of the contradictions and conflicts of desire to be salvation and refused to forgive, and these were mainly from the hearts of people: actor betrayal love for redemption and fear to moral refuse to forgive Hannah; Hannah due to concentration camp killing victims for redemption, and the victims refused to forgive Hannah for hate; eventually Hannah chose to give up life for forgiveness.

\section{Conclusion}

The novel The Reader is moved after reading, the novel is more wonderful than the plot of the film, its readers culture is relatively high, In relation to the character form and the movie content, the novel is more rigorous, more sophisticated, screen can not do this. With the emergence and development of the film and the novel, not only reflected the writer's writing style, but also there is unique style of the times: In addition to the material and unique humanistic spirit, the total variation range is not wide, these features of the description of characters, beautiful pictures and delicate emotion is constitute a classic movie. The Reader is a story of betrayal and redemption, the film is full of love and sex and the story of love betrayal, but it is also a beautiful love story that need to carefully care. The Reader not only has reflection and criticism of the war, morality, ethics, love, betrayal, redemption and human nature, which contains emotion is very complex and the guilt of the historical need to face by the world.

\section{Acknowledgments}

The work was supported by the Research Project of Humanities and Social Sciences in Universities of Jiangxi Province with the project number WGW1419 with the project name The Study of The Reader from the Perspective of Multiple Theories.

\section{Reference}

[1] Dong Qiqi, Speaking and Listening -- A multidimensional perspective of the human nature of The Reader [J]. Modern Literary Magazine, 2010,02:104-106. 
[2] Chen Chen. The road to the recovery of human nature -- An interpretation of the image of Hanna in The Reader [J]. Journal of HeFei University of Technology (Social Sciences), 2010,03:103-106.

[3] Wang Meng. The Reader: From the novel to the film [J]. Film Literature, 2010,22:56-58.

[4] Liu Pengli. The Interpretation of the historical consciousness of The Reader [J]. Film Literature, 2010,18:108-109.

[5] Zhang Guolong, Historical fable writing and Transcendence of the grand narrative tradition of German growth novels -- a review of The Reader [J]. Foreign Literature, 2007,05:112-118,128.

[6] Zhang Huijuan. "Enlightenment", "Sin sense" and "Stray": The Reader in "reading" the aesthetic metaphor interpretation [D]. Guangxi Normal University, 2014.

[7] Zhang Minjing. The sense of "shame" in The Reader [D]. Southwest Jiao Tong University, 2011

[8] Huang Jie. Moral transgressors confession -- from the perspective of ethical literary criticism of The Reader [D]. Wuhan University of Technology, 2012

[9] Liao Junlan. Self help of love and Crime -- on the metaphor structure of The Reader [J]. Anhui Literature, 2008,02:163-165.

[10] Mi Gaofeng. The film The Reader: The Love Elegy behind the text read aloud [J]. Film Review, 2011,03:47-49.

[11] Zhang Yue. The Reader: love fable and human nature trial [J]. Hundred Schools In Arts, 2009, S1:141-144.

[12] Wu Tingting. The reader from the perspective of "myth archetype criticism" [J]. Film Literature, 2013,10:25-26.

[13] Ding Weixiang, Fang Chunguang. Reading and enlightenment, Salvation and Unrestrainedne -Metaphorical meaning of Enlightenment of reading on The Reader. [J]. Journal of PLA University of foreign languages, 2013,04:121-126.

[14] Huang Dan. Last summer fantasy rose - The gossip adaptation of film The Reader [J]. Film Art, 2012,01:104-109.

[15] Hu Minqi. Growth fable author identity and narrative strategy -- a comment on Bernhard Schlink of The Reader[J]. Appreciation of Literature Masterpieces, 2012,17:151-153.

[16] Zhao Yamin, Zhang Jun. Let the tragedy no longer repeat -- multi - Theme interpretation of The Reader [J]. Appreciation of Literature Masterpieces, 2012,21:86-88.

[17] Wang Damin. We are reading aloud, Bernhard Schlink of The Reader[J]. Appreciation of Literature Masterpieces, 2012,28:59-62.

[18] He Jieyun. Comparative analysis of the Chinese version of the novel The Reader [D]. Shanghai Jiao Tong University, 2011

[19] Gu Chunxia. Soul Salvation from Maslow's humanistic psychology interpretation of the movie The Reader in Hannah's self realization [J]. Litbraturb Bducation, 2010,03:34-36. 